\title{
Changes in Supervision as Counselors and Supervisors Gain Experience: A Review
}

\author{
Everett L. Worthington, Jr. \\ Virginia Commonwealth University
}

\begin{abstract}
Evidence bearing on whether and how counselors and supervisors receive or give different types of supervision of psychotherapy as they each gain experience was investigated. Theories describing changes in supervision of counselors as they gain experience are reviewed. Most are similar to each other. They posit changes in the supervisee, with supervision environments being matched to the changing needs of the supervisee. There are three theories concerning how the supervisor changes as he or she gains experience. Findings from empirical studies are consistent with theories of counselor development but only weakly supportive of the theory that actual supervision environments are matched to supervisee needs. Findings from empirical research on changes in supervisors as they gain experience reveal few differences in supervisors at any level beyond the master's degree.
\end{abstract}

Presumably, therapists and supervisors age like wine. In this article, I sample their sounds, sights, bouquets, and tastes as they gain experience. Supervision of prepracticum counselors is not covered in this review (for a recent review, see Kurtz, Marshall, \& Banspach, 1985). Rather, this article is a summary of supervision of counselors from their first practicum and beyond. First, the issue of what supervision should be is discussed. Then research on changes in supervision as counselors gain experience is reviewed. Last, research on changes in supervision as supervisors gain experience at supervision is examined.

\section{Theories of Changes in Supervision With Experience}

We assume (and hope) that counselors and supervisors learn and improve as they gain experience. As professional helpers who have invested time, energy, and professional identity in

Everett L. Worthington, JR., PhD, is Associate Professor of Psychology at Virginia Commonwealth University. His current research activity includes supervision of psychotherapy, religious counseling, adolescent pregnancy, and other topics relating to marriage, family, and values.

CORRESPONDENCE CONCERNING THIS ARTICLE should be addressed to Everett L. Worthington, Department of Psychology, Virginia Commonwealth University, 800 West Franklin, Richmond, Virginia 23284-0001.

This article is a reprint from Professional Psychology: Research and Practice, 1987 Vol. 18, No. 3, 189-208. the wine rack of learning helping skills, we psychologists have a vested and emotional interest in finding that change occurs with experience. Should we find that time and experience turn our wine to vinegar, we would be incredibly threatened. In general, we assume that change occurs and ask how counselors and supervisors change as they gain experience. This has generated several conflictual issues that must be understood in order to understand the research on changes in supervision resulting from changes in experience.

\section{Conflicts in Supervision Theory}

One conflict is this: Should supervision be proactive or reactive? Some supervision is driven by an agenda: Sessions are planned; goals are clearly identified; interventions are usually initiated by the supervisor or even planned before a supervision session. Another type of supervision is reactive: Goals are identified, but the supervisor awaits critical incidents and intervenes when those incidents arise, not initiating his or her agenda. Should this supervision style change as a counselor gains experience? In practice, most training of prepracticum students and often students in early practica is more proactive than reactive. As the counselor becomes more proficient, the supervisor becomes more reactive. Is this desirable? If we could identify the component skills of advanced counseling or even master-level coun- 
Table 1

Supervision of the Developing Counselor

\begin{tabular}{lc}
\hline \multicolumn{1}{c}{ Stage/stage of counselor } & Supervisor behaviors \\
\hline 1. Imitative learning & Fleming (1953) \\
2. Corrective learning & $\begin{array}{c}\text { Anxious supervisees learn by imitating their supervisors, who } \\
\text { give suggestions and demonstrate ways of counseling } \\
\text { Supervisor corrects inaccurate interpretations and techniques } \\
\text { (less support is necessary because counselor self- } \\
\text { confidence is relatively high) } \\
\text { 3. Creative learning }\end{array}$ \\
& $\begin{array}{c}\text { Supervisor investigates the supervisee's personal reactions to } \\
\text { the client and how these affect counseling }\end{array}$
\end{tabular}

Grotjahn (1955)

1. Period of preparation

2. Elaborate on therapist's knowledge of client

3. Working through
Provide technical help and respect and encouragement, restrain the counselor from beginner mistakes (hasty reassurance and support)

Help the therapist to understand the client's personality dynamics and psychopathology

Help the therapist to understand and deal with own feelings and conflicts that are part of the therapeutic process

Hogan (1964)

1. Dependent on supervisor: Neurosis bound, insecure, uninsightful, highly motivated, imitative

2. Dependency-autonomy conflict: Struggle between overconfidence and being overwhelmed, ambivalent, fluctuating motivation; personal therapy with someone other than supervisor is recommended

3. Conditional dependency: Increased professional self-confidence; greater insight, especially about neurotic and healthy motivations; more stable motivations

4. Master psychologist: Personal autonomy, insightfulness with motivation, need for confrontation
Tuition (identifying predictable outcomes), interpretation, support, awareness training, exemplification

Support, ambivalence clarification, exemplification, some tuition

Sharing as peers, examplification, confrontation

Sharing, confrontation, mutual consultation

Ard (1973)

1. Perceptorship: Student has need of orientation

2. Apprenticeship: Requests specific instruction

3. Mentorship: Student demonstrates work and wrestles with personal issues

4. Sponsorship: Student is largely competent

5. Peership: Student has emerged from training to full professional status
Orients beginning student

Gives specific instructions

Critiques the work of the supervisee, helps supervisee in selfexamination

Instills further confidence in an already competent counselor

Establishes coequal relationship after termination of formal supervision

Gaoni \& Neumann (1974)

1. Teacher-student stage

2. Apprenticeship

3. Developing the therapeutic personality

4. Mutual consultation among equals

Littrell, Lee-Borden, \& Lorenz (1979)

1. Initial

2. Counselor-therapeutic

3. Teacher

4. Consultation

5. Self-supervising
Goal setting, clarification of nature of supervision and its components

Supervisor acts as counselor to supervisee

Supervisor teaches supervisee the skills of counseling Cooperation; supervisor and supervisee work together Supervisee systematically seeks to improve own counseling through self-observation 
Table 1 (continued)

Stage/stage of counselor

1. Attempts to define boundaries between the "counselor" and the "person"

2. Begins to define own identity; not content to initiate; experiments with different styles; begins to disagree with supervisor

3. Increased empathy, more highly differentiated interpersonal orientation, no longer a disciple of any given technique, tolerant, can work with a variety of clients

4. Capable of independent practice, willful interdependence with others, integrates the standards of the profession within a personal value system
Supervisor behaviors

\section{Stoltenberg $(1981)^{\mathrm{a}}$}

Encourages autonomy within a normative structure; encourages risk taking, acts as teacher, integrates theory and practice, does not answer all questions correctly, attends to the supervisee's behavior in supervision as well as in counseling, gives opportunities to observe the supervisor

High autonomy, low normative pressure; instructs the trainee in new skills and gives advice when necessary

Increased emphasis on sharing; an exemplification by both partners, appropriate professional and personal confrontation; supervisor might acknowledge own weaknesses

Consultation given when deemed appropriate by the supervisee

\section{Hart (1982)}

1.

2.

Didactic instruction by the supervisor, acquisition of the case conceptualization and intervention skills

Additional work on supervisee skills but also supervisory feedback on supervisee therapeutic work, some work on personal awareness

3.

Integration of skill development with personal awareness, especially as it applies to clients

\section{Yogev (1982)}

1. Role definition: Student acknowledges commitment to becoming a therapist, demystifies therapy, experiences anxiety, feels inadequate, recognizes some strengths

2. Skill acquisition: Learning the skills of counseling

3. Solidification and evaluation of practice
Helps student to define role, clarifies expectations in supervision, evaluates the supervisee

Observation of student, possible cotherapy with the supervisor

Uses both emotional aspects and didactic and skill-practice aspects

\section{Blount (1982)}

1. Adequacy versus inadequacy

2. Independence versus dependence

3. Conditional dependency versus individuation

4. Professional integrity versus personal autonomy
Supportive relationship, awareness training, modeling, didactic skills instruction

Exemplification and integration of dynamics, advanced skill development

Greater autonomy and appropriate confrontation, encouragement of peer relationship

Shaping and collegial consultation, self-supervision, supervision of others, mentoring

Wiley (1982)

Expands on Stoltenberg's model of counselor complexity but identifies five critical issues that are behaviorally defined for each of Stoltenberg's four stages
Expands on Stoltenberg's model of supervision environments but identifies five critical issues that are behaviorally defined for each of Stoltenberg's four stages

Loganbill, Hardy, \& Delworth (1982)

1. Stagnation: Naive unawareness, simplistic dualistic thinking; counseling may lack intensity; linear problem solving, low self-concept, extreme dependence on the supervisor
Supervisors are thought to assess and evaluate supervisee and to have five types of interventions: facilitative, confrontive, conceptual, prescriptive, and catalytic interventions

(table continues) 
Table 1 (continued)

\begin{tabular}{lc}
\hline \multicolumn{1}{c}{ Stage/stage of counselor } & \multicolumn{1}{c}{ Supervisor behaviors } \\
\hline \multicolumn{1}{c}{ Loganbill, Hardy, \& Delworth (1982) (continued) } \\
$\begin{array}{l}\text { 2. Confusion: Instability, conflict, fluctuation between } \\
\text { feelings of incompetence and feelings of great }\end{array}$ & $\begin{array}{c}\text { All types of interventions may be appropriate for any stage } \\
\text { on any issue }\end{array}$ \\
$\begin{array}{l}\text { ability; supervisor may be thought of as all- } \\
\text { knowing or incompetent }\end{array}$ & \\
3. Integration: Calm reorganization, a refreezing of \\
attitudes, basic acceptance of self and of limitations; \\
supervisor is seen as a realistic person with strong \\
and weak areas
\end{tabular}

\section{R. Miller (1982)}

1. Quiescence

2. Early exploration

3. Imitation

4. Partial autonomy

5. Autonomy
Interventions are represented along three continua: Intrusivereflective, oppositional-supportive, and prescriptiveelicitive

Sansbury (1982)

1. Prepracticum: Basic listening skills and assimilation of the role of counselor

2. Practicum: Develops new therapeutic techniques; improves conceptualization, refines personal theory, develops competence, establishes limits of responsibility for self and client

3. Internship: Broadens and refines understanding of clients, learns types of clients that are best helped, examines personal issues, learns reliance on self
Evaluative feedback, needs assessment; models good counseling skills, reinforces and supports students

Analyzes cases; helps resolve counselor-client impasses; promotes counselor understanding through confrontation, role reversals, interpretation, and feedback; teaches supervisees to ask for help in supervision

Confronts supervisee on differences in talk and behavior, supports increased risk taking, helps supervisee with personal issues, assists supervisee to self-evaluate

S. R. Friedlander, Dye, Costello, \& Kobos (1984)

1. Ambiguity in supervisee

2. Recognition of limits of therapeutic conditions

3. Discovery of therapy as deep communication

4. Eclecticism in light of client's needs ${ }^{c}$
Helps supervisee deal with demands for wide-ranging tolerance of ambiguity; emphasizes learning to learn

Helps supervisee to see difference in theory and practice; accepts mistakes and unanticipated client responses; helps to deal with guilt over failures

Helps to take focus off techniques and onto human relationships

Helps to develop a repertoire of interventions; helps to apply on the basis of sensitive assessment of clients

Hess (1986)

1. Inception: Confusion, unanchored experience, anxiety, identity formation, adequacy versus inadequacy

2. Skill development: Choice of theory, dependence versus independence

3. Consolidation: Skills become "owned," new skills develop; may supervise less experienced colleagues

4. Mutuality: Establishes professional identity, conditional dependency versus individualism
Helps to identify experience with cognitive maps for handling experience; encouragement, support, mutual trust

Induces students to try out techniques; rehearses techniques with them; gives corrective feedback

Helps students to learn new skills; encouragement

Mentoring; collegial supervision; focuses on how therapists' personality affects the case; stages are "spiraled" (e.g., repeated at different depths)

\footnotetext{
a Uses Hogan's (1964) four stages (dependent, dependency-autonomy conflict, conditional dependency, master counselor) but expands on them.

b There are thought to be eight critical issues: competence, emotional awareness, autonomy, theoretical identity, respect for individual differences, purpose and direction, personal motivation, and professional ethics. For each issue, the supervisee is thought to negotiate the three stages listed.
}

${ }^{\mathrm{c}}$ All four issues may arise simultaneously but may be resolved in the order given. 
seling with the same precision with which we articulate basic listening skills, would supervision still largely be reactive at advanced counselor levels? Or does our inability to precisely identify higher order counseling skills shape our theory of supervision?

Another conflict in supervision is whether the counselor should learn the theory of the supervisor or whether the supervisor should adapt his or her methods to work within the theoretical framework of the supervisee. A supervisor's position on this issue may change as the supervisee gains experience. Beginning trainees might be taught a doctrinaire way of counseling, whereas interns and postdoctoral supervisees are allowed more freedom. An exception to this generalization is when the supervisee explicitly asks to learn the counseling style of the supervisor (e.g., learning strategic family therapy from Jay Haley, or Paul Wachtel's learning behavioral counseling from Gerald Davison). Even in these exceptions, though, what is taught, how fast it is taught, and what is assumed to be known differs with the experience level of the counselor.

Whether and how supervision changes as counselors gain experience also depends on the supervisor's beliefs about supervision and counseling (Bartlett, Goodyear, \& Bradley, 1983). Some models of supervision are based on counseling theories, which are adapted and generally used consistently with supervisees. The component parts of the counseling theory are identified and taught to the supervisees, and the methods by which they are taught are often some of the same methods that are used with clients within counseling. Supervision changes with skill level of the therapist, but changes might be more content specific than process specific. A second approach to supervision is not based on a specific counseling theory. Counselors are thought to change in needs and abilities as they gain counseling experience. It is assumed that supervision should be matched to the level of the counselor. According to this developmental model, how a supervisor intervenes is determined by the supervisor's view of the stages of counseling, by the experience that the supervisor has with counselors of varying experience, and by the supervisor's assessment of the level of both performance and knowledge of the supervisee. The content of the supervis- ee's theory is generally irrelevant in this developmental approach.

\section{Supervision of the Developing Counselor}

Much of the research on how supervision changes with time has been done by developmental theorists who have described supervision apart from the supervisor's theory of counseling. Several such theories have been articulated (see Table 1 for a summary). Generally, in these theories an implicit stage theory of counselor development is assumed, and supervisory behaviors that are thought to be consistent with the hypothesized level of development of the counselor are specified. What is surprising is that few researchers have directly investigated the actual development of counselors as they gain supervised and unsupervised experience. One notable exception is Hill, Charles, and Reed (1981), who found that counselors in their doctoral program in psychology (at the University of Maryland) progressed through four stages. The first stage involved self-consciousness of the counselor and attention to their internal experiences, sometimes to the exclusion of understanding the clients' experiences. During a second stage, counselors adopted a counselor's stance in which they used some standard approach to counseling. Therapeutic failures were explained in terms of the counselors' inability to execute counseling skills prescribed by the theory. Application of the theory was generally rigid; clients were fit into a procrustean bed of prescribed theory. As the counselor gained expertise in the chosen model, however, the occasional therapeutic failures did not stop, though they decreased in numbers. These anomalies, to use a Kuhnian term, generally introduced uncertainty into the counselor's theorizing. There occurred a third stage, which spanned late practicum, internship, and early (and sometimes later) professional experience, during which the counselor became confused over the anomalies and rejected the original theory in favor of eclecticism. Sometimes the counseling theory that guided their practice was left unarticulated. At other times theoretical propositions were inconsistent and contradictory. If counselors progressed beyond this stage, they articulated a reasonably clear and internally consistent personal theory of counseling and behaved consistently with that articulation. 
This empirically derived model of counselor development is similar to the theorizing of Hogan (1964). Hogan hypothesized four stages of counselor development. Beginning counselors were thought to be insecure, neurosis bound, and uninsightful; second-stage counselors were thought to struggle with dependency-autonomy conflicts and to have supervision relationships characterized by ambivalence; in the third stage, the trainee was thought to gain self-confidence and to evidence more stable motivation; and the fourth stage was termed master psychologist and was hypothesized to be characterized by personal autonomy and self-assurance.

Hogan (1964) proposed that ideal supervision environments promote counselor growth in each stage. If the environment was matched to the developmental needs of the counselor, then optimal growth and improvement of the supervisee should result. Hogan's operationalization of supervision behaviors ideal for such stage of supervisee development was skimpy in comparson to the specification of the supervisee's development. Nonetheless, this seminal paper provoked both subsequent theorizing (Stoltenberg, 1981) and research (Reising \& Daniels, 1983).

Stoltenberg (1981) expanded Hogan's (1964) model, terming his elaboration the counselor complexity model. As the counselor develops, he or she is thought to become more cognitively complex. Stoltenberg accepted Hogan's speculations about the development of counselors and more carefully described how supervisors might create growth-producing environments. During the first stage, the supervisee is provided with a structure and encouraged to develop autonomy within the safety of the structure. In the second stage, the supervisor deals with identity issues by offering new skills and advice from which the supervisee can choose. In the third stage, increased sharing and collegiality exist, and personal confrontation is sometimes sought and given. In the master counselor stage, consultation is given when sought.

Loganbill, Hardy, and Delworth (1982) identified three stages of counselor development: stagnation (naive unawareness), confusion, and integration. These stages are similar to stages identified by Hill et al. (1981) as well as by Hogan (1964) and Stoltenberg (1981). However, Loganbill et al.'s (1982) added twist was that counselors need to resolve eight critical issues before becoming master counselors: competence, emotional awareness, autonomy, theoretical identity, respect for individual differences, purpose and direction, personal motivation, and professional ethics. The counselor is thought to resolve the issues independently of each other. Thus the counselor could be in any of the three stages (stagnation, confusion, or integration) with any issue. The supervisor's task is to assess the level of development on the issue that is being dealt with in supervision and to promote growth to the next level of development on that issue. Loganbill et al. thus proposed the most flexible theory of the development of the counselor. Hess (1980) was similarly flexible within a less completely developed theory. He proposed that development of the counselor occurs in spirals of increasing complexity rather than linearly.

Extant stage theories of supervision are analogous to California wines, showing nuances in quality and subtlety but often being quite similar to each other. There are some deficiencies in the current theories. For example, each theory of supervision depends on a picture of counselor development that is clear in what it says but is painted with broad brush strokes. From afar the shapes are noticeable but on closer inspection there are no details. The descriptions of counselor development rest on scant research. There is no specification of what higher order counseling skills are or when each level of counseling skill might come into ascendency. For example, it is generally agreed that basic listening skills are the building blocks of therapy and that advanced empathy, confrontation, focusing, conceptualization, and intervention skills are necessary to good counseling. However, when are counselors most ready to learn conceptualization? When and how does the counselor show readiness to learn how to use the conceptualization arrived at in the supervision session or in private thought to help the client adopt that conceptualization as his or her own? When does the counselor learn to deal with defensiveness and resistance? Obviously, all of these skills are needed with most clients, but counselors in their first practicum cannot learn everything. Concepts are postponed until less self-consciousness and anxiety inhibit the counselor. A specification is needed for how and when the supervisor can tell that the counselor is receptive to learning. 
Another deficiency with current developmental stage theories of supervision is that they are primarily stage theories rather than theories of how transitions take place between stages. They specify-albeit broadly-what the counselor and the supervisor experience and do during each stage. But how does the supervisor promote movement from one stage to another? A transition theory of counselor development and consequent supervisor behavior is sorely needed.

\section{Supervision by the Developing Supervisor}

Few theorists have addressed how supervisors change as they gain experience. Because there has been little attention to this problem, research on the issue has been helter-skelter.

Bernard (1979, 1981, 1982) described how supervisors can be trained to increase their awareness of options during supervision. She outlined a training method that is equally applicable to beginning and experienced supervisors. Three segments constitute her 16-hr training module: baseline data gathering, exposure to models of supervision, and evaluation plus ethical dilemmas. In the first segment, supervisors identify the focus of the supervision that they have audio- or videotaped. Three areas of focus are defined: process skills, which include how the counselor behaves during counseling; conceptualization skills, which are concerned with how the counselor thinks about counseling; and personal skills, which include how the counselor reacts to counseling. Supervisors determine the approximate weighting that they currently give to each focus. Three roles are also identified: teacher, consultant, and counselor. Bernard $(1981,1982)$ reported that supervisors often become aware of a discrepancy between intention and performance. The most common discrepancy is the case of the supervisor who thinks that he or she uses the counselor role most often but finds, upon objective selfobservation, that he or she usually uses the teacher role (see also Hess \& Hess, 1983). In the second segment, Bernard broadened the theoretical horizons of the supervisor. She explained four approaches to supervision and had the supervisors use each model briefly: Bernar's (1979) discrimination model; Interpersonal Process Recall (Kagan, 1980); microtraining (Forsyth \& Ivey, 1980); and live supervision (con- trasting with retroactive supervision rather than dead supervision). In the third part of her program, Bernard discussed evaluation in supervision, showing supervisors the difference between pinpointing evaluation issues and communicating the issues to the supervisee (see Tyler \& Weaver, 1981, for a discussion). She discussed ethical behavior with the use of vignettes that pose issues and require decisions that have generally not been thought through by the supervisors. Bernard's training is systematic, and she reported that it was useful both for the neophyte and the experienced supervisor. She found that the experienced supervisors generally show more responsivity to the material than the inexperienced supervisors.

Alonso (1983) proposed a different type of theory of supervisor development. She considered how a supervisor might change throughout the entire professional life cycle, moving from novice to midcareer to late-career concerns. At each stage in the career of the supervisor, the supervisor must wrestle with three issues: self and identity, the relationship between therapist and supervisor, and administration. The supervisor in each of the stages resolves the issues differently because the demands of life and professions differ at each life stage.

Hess (1986) noted the paucity of theories of development of the supervisor and has proposed a three-stage model of supervisor development. In the beginning stage, the new $\mathrm{PhD}$ assumes the mantle of the supervisor by virtue of graduation rather than by training or experience. The new supervisor must therefore deal with the role status change from trainee to trainer, supervisee to supervisor. Because only about one third of interns receive training in supervision (Hess \& Hess, 1983), lack of awareness of the structure of supervision and the techniques of supervision make the supervisor sensitive to the criticism of peers and students and often promote selfconsciousness. The new supervisor often copes with the self-doubts and ambiguity by adopting a concrete structure for supervision and focusing on techniques of counseling or on client diagnosis.

In the second stage, exploration, the supervisor has gained confidence and competence and is often able to baffle and amaze the supervisee with feats of apparent psychological legerdemain. Supervision is accepted as a professional activity of value, and the supervisor's enthusi- 
asm promotes increased student interest in counseling. Two pitfalls are common to the second stage of supervisor development: giving supervision that is too restrictive or too intrusive.

The third stage of development is characterized by continued and increased respect from students and respect for students. More attention is given to the student's learning agenda, and more relationship per se occurs (rather than cognitive attention to relationship). Supervisors are sought because they are perceived to be excellent teachers of psychotherapy. Gratification is achieved when the supervisee excels rather than when the supervisor is recognized as being a good supervisor.

Despite the beginning of theorizing about the professional development of the supervisor, the field is at a rudimentary level, like grapes fermenting in the sun in comparison to making California wines (i.e., theories about the development of supervisors). Missing is any explication about (a) how supervisors might behave at different levels of development, (b) differentiation between development of counseling skills and supervision skills, (c) whether continuing to counsel clients impedes, accelerates, or does not affect supervision competence (and if it affects it, how), (d) the ways in which supervisors learn their trade, (e) how a supervisor develops and modifies his or her theory or model of supervision with experience, (f) what types of experiences and critical incidents help supervisors to improve, (g) what might impede the development of a supervisor, (h) how other professional experiences dovetail with development of supervision skills, and (i) whether a supervisor can provoke critical incidents in supervision to help the supervisee improve. An explicit, testable theory of the developing supervisor is needed in order to drive and focus research concerning the supervisor. The theory must transcend the descriptive models currently available and identify theoretical variables of import within the larger framework of psychology. Whatever the thrust of the theory, new thinking is needed in order to further the understanding of the supervisor and how he or she can help people to learn psychotherapy.
Supervision of the Developing Counselor: Empirical Research

\section{Historical Perspective}

The types of training that counselors with different levels of experience receive has changed over time (Leddick \& Bernard, 1980). Early in the history of supervision, psychoanalysis dominated the field and supervisees underwent training analysis, presumably learning psychotherapy skills through experiencing the role of client and through observing the training analyst at work. Later, it was thought that teaching of theories of therapy and personality development occurred in the classroom, whereas training in counseling occurred at practicum sites or counseling agencies. As Carl Rogers, Robert Carkhuff, Charles Truax, Allen Ivey, Gerard Egan, Steven Danish, and others developed technologies of training, though, skill training began to occur earlier in programs that trained therapists. Currently, counselors are expected to enter their first counseling practicum already proficient at beginning counseling skills. Technologies continue to advance. There is increasing use of videotaping, bugs in the ear, and even computer simulation (Phillips, 1984). The component skills of advanced psychotherapy are being identified and studied, and process models are being explicated. With increasing sophistication, we researchers might expect the types of training offered to therapists to continue their evolution.

\section{Methodology}

In general, studies of supervision as counselors gain experience have been of two types: investigations of one level of counselor (beginning counselors or post-master's counselors) and investigations of several levels of counselor simultaneously (see Table 2 for a summary of the method and findings arranged by those categories).

Samples for four of the six studies of beginning counselors were drawn from the University of Missouri. The other four studies were drawn from one practicum site also. This is a serious restriction in generalizing the results because Worthington (1984a) found that the supervision given at different university counseling centers

(text continues on page 149) 


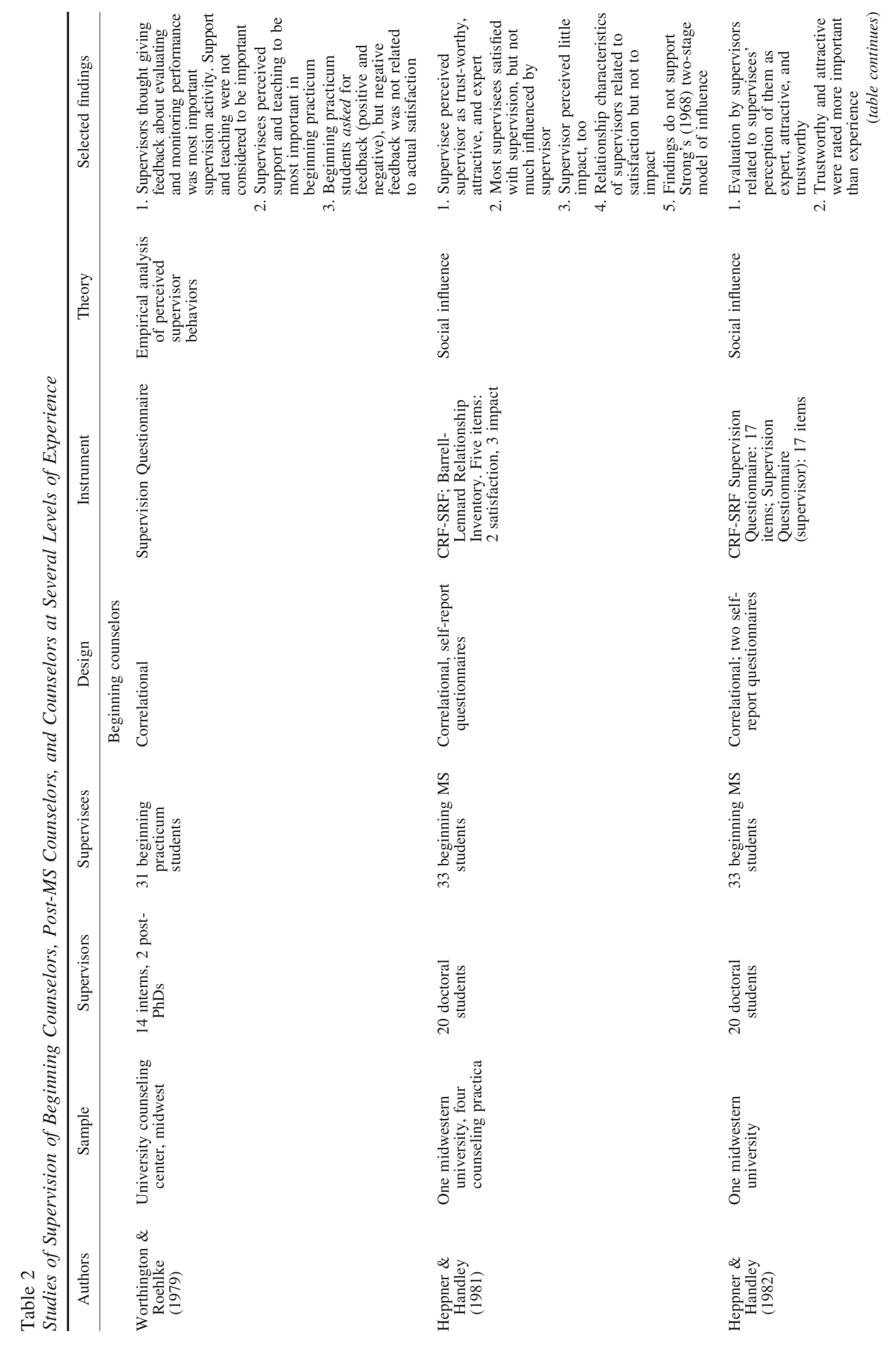




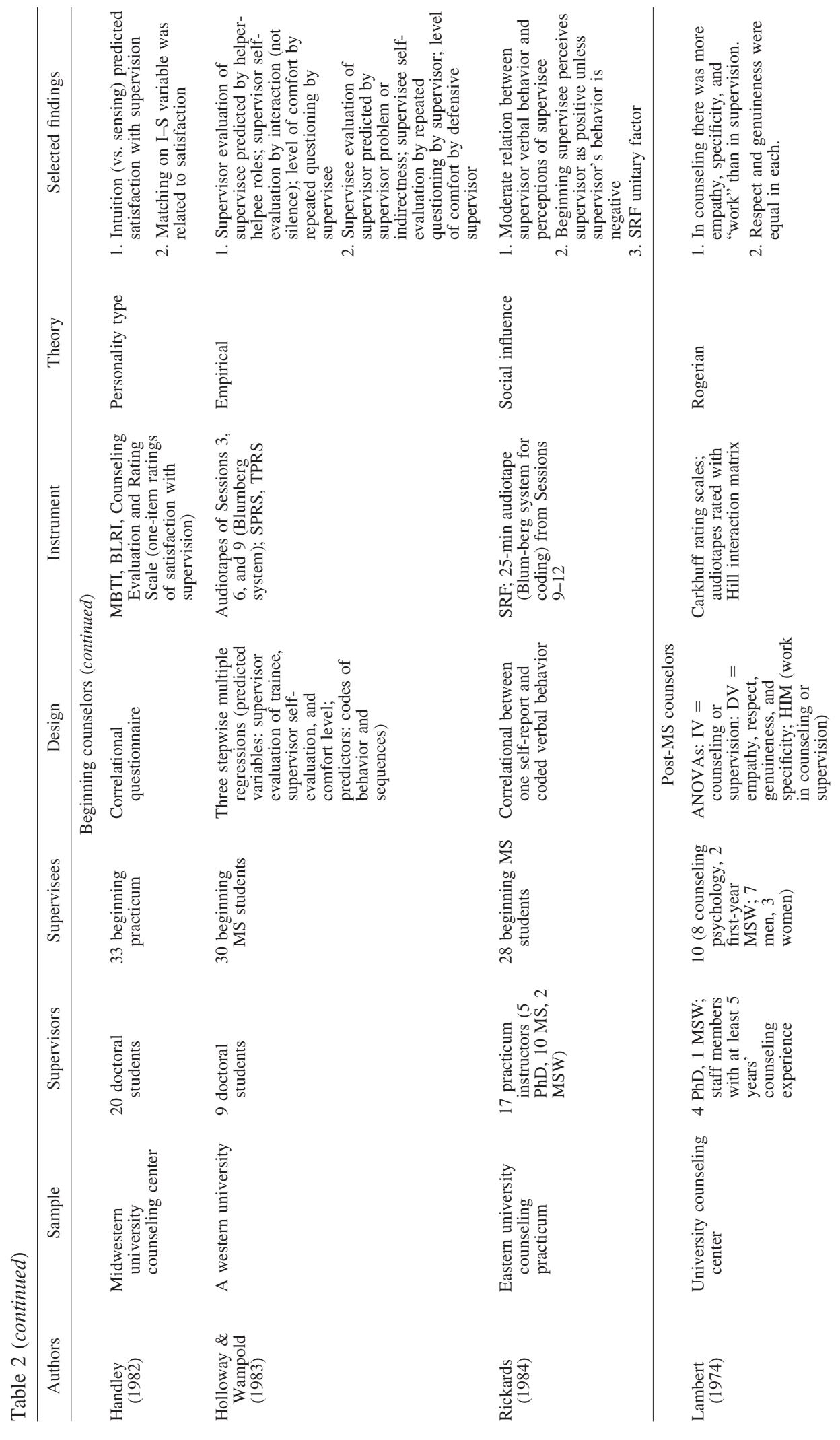




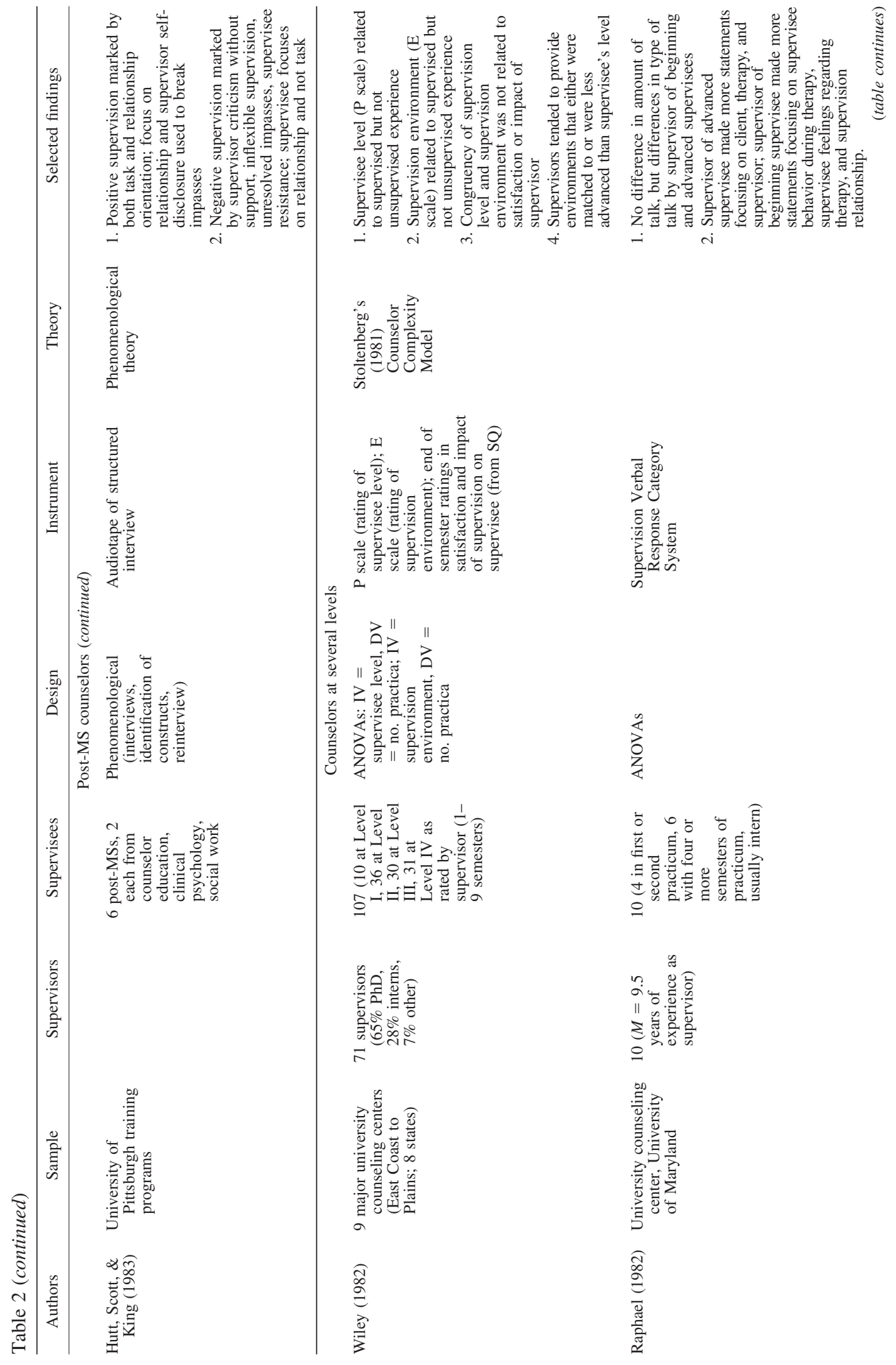




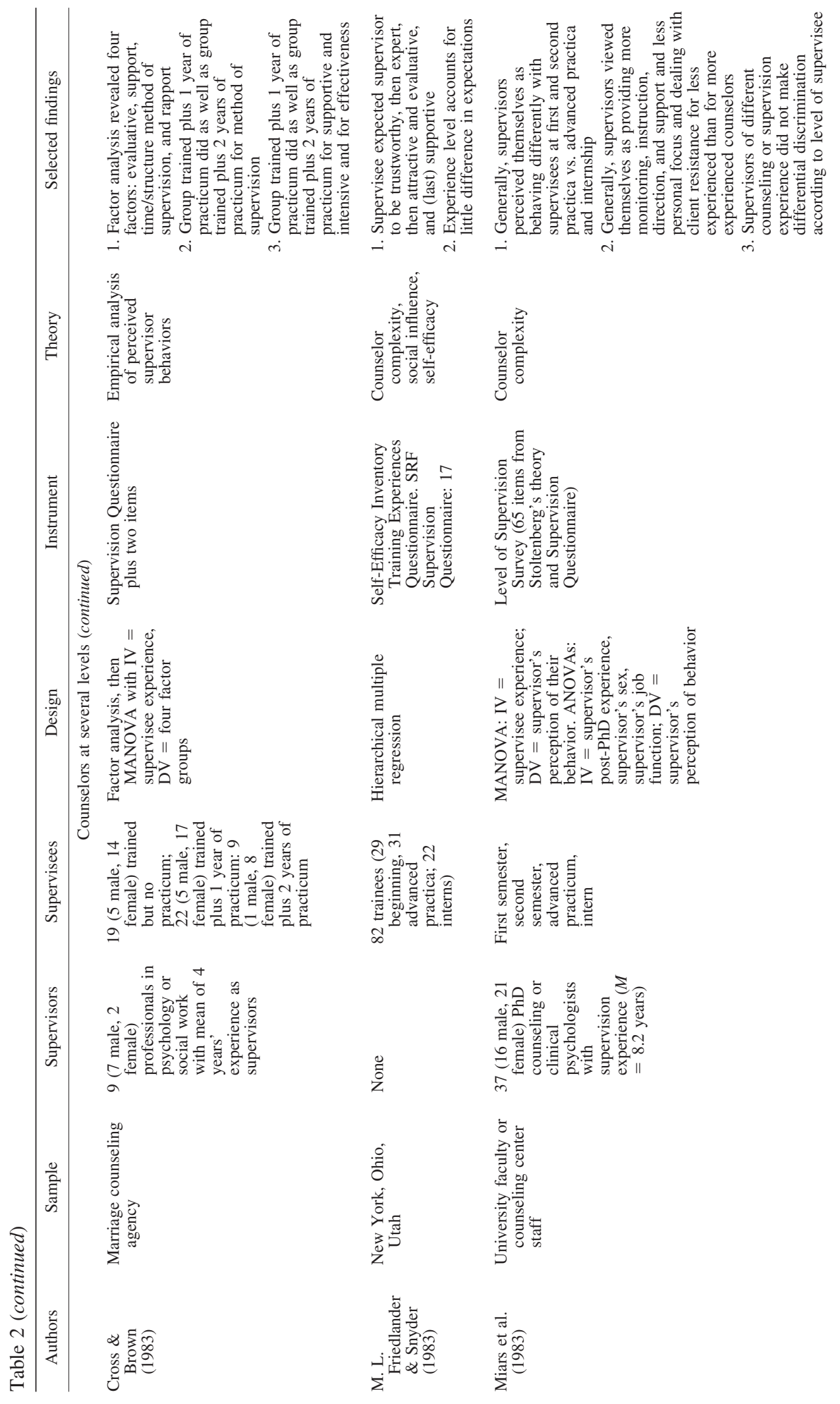




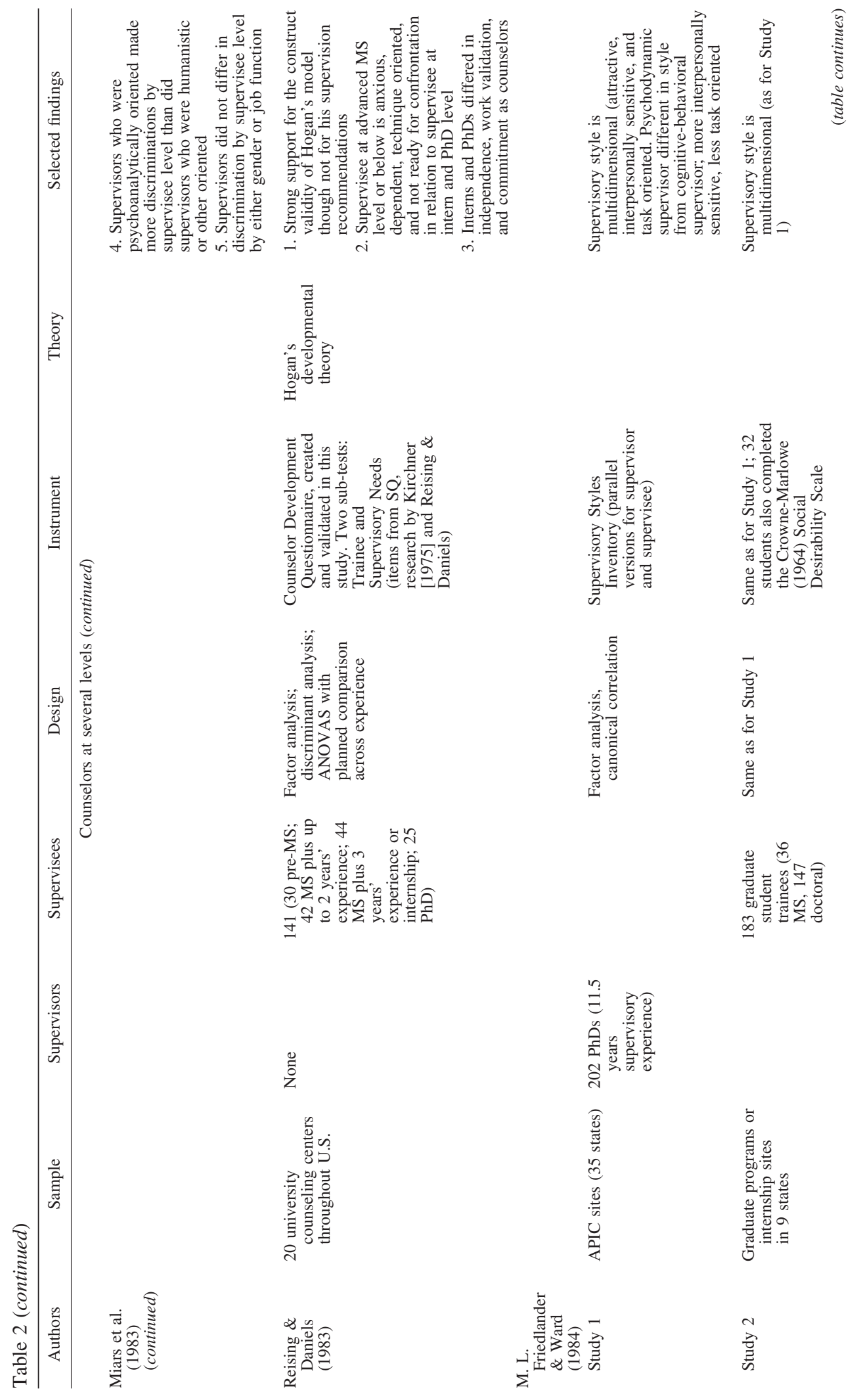




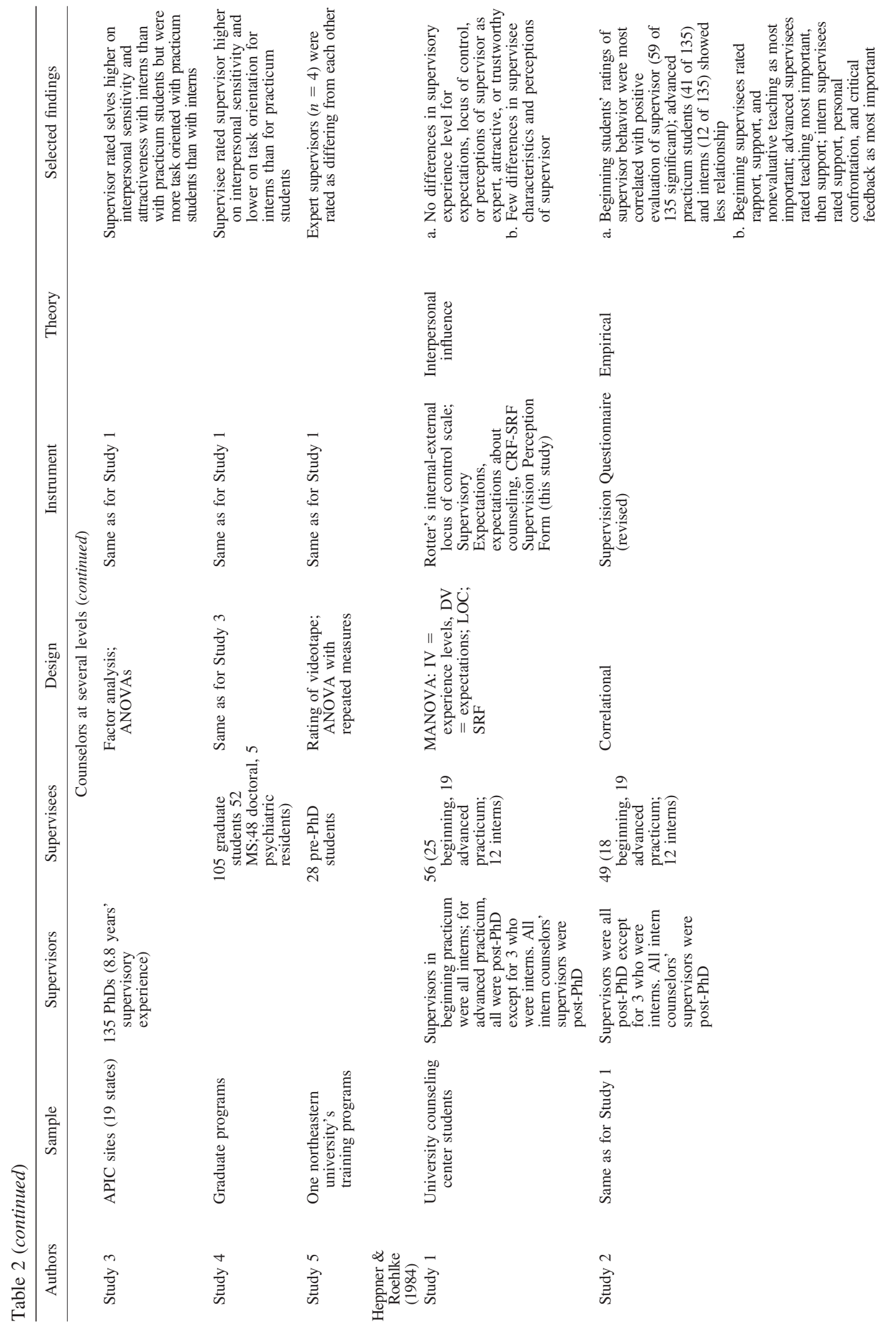




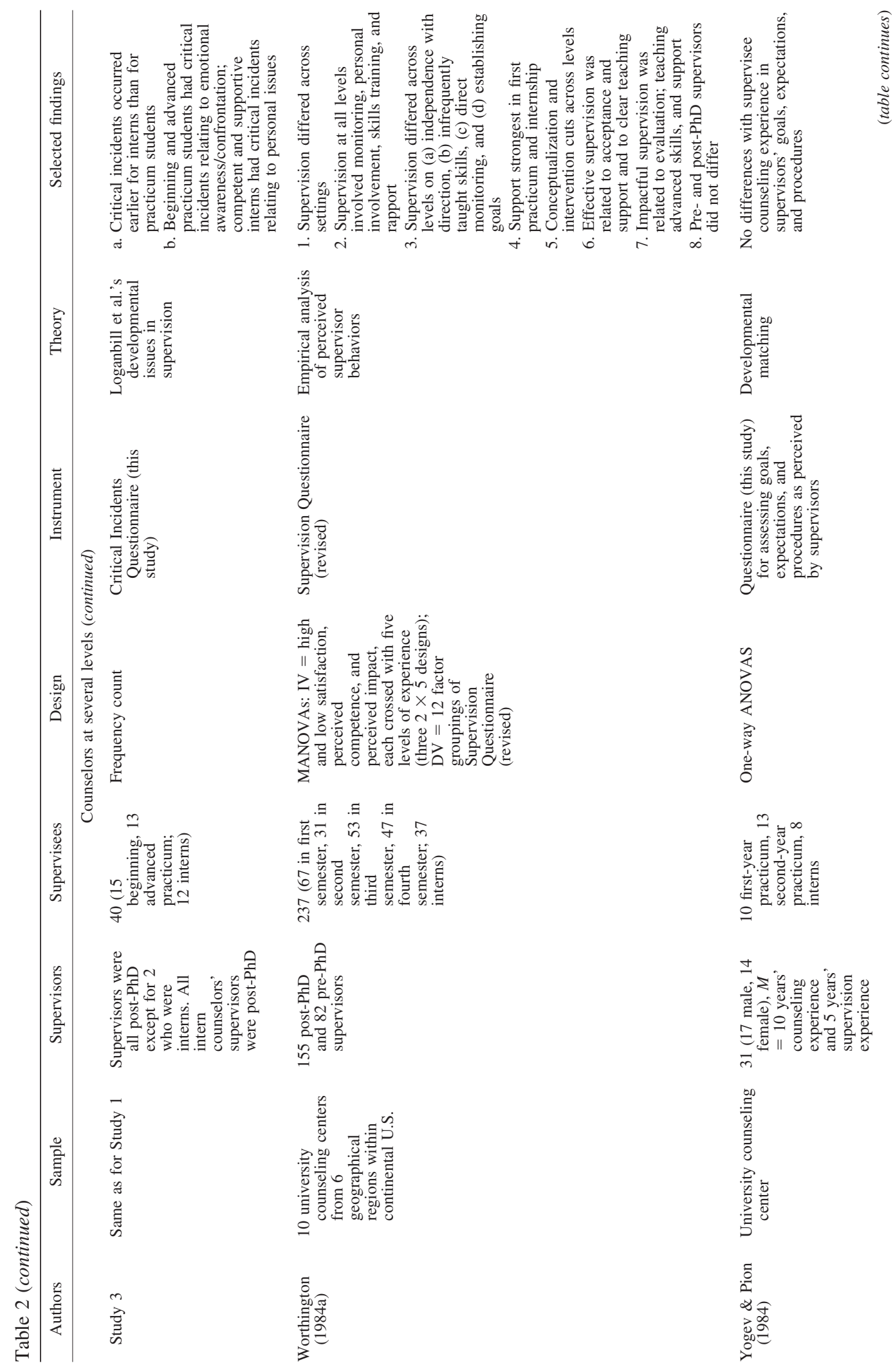




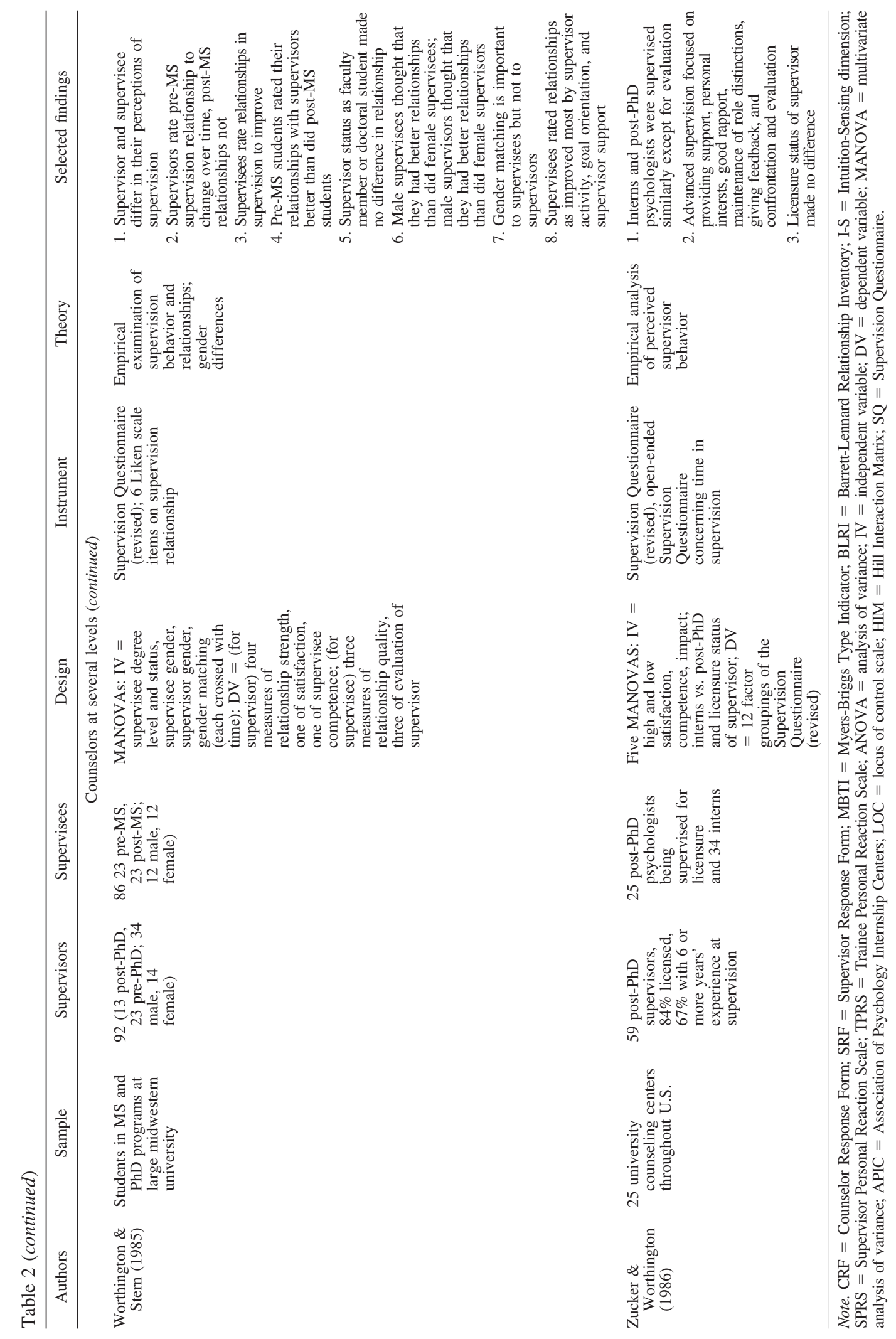


throughout the United States differed. Three self-report instruments have been used with regularity: the Supervision Questionnaire (SQ) or a modification of it (Worthington \& Roehlke, 1979), a modification of the Counselor Response Form (CRF; Barak \& LaCrosse, 1975), and the Barrett-Lennard Relationship Inventory (Barrett-Lennard, 1962). Researchers in three studies directly measured supervisor behavior (Holloway \& Wampold, 1983; Lambert, 1974; Rickards, 1984). Two used the Blumberg Coding System (Blumberg, 1980) to categorize responses, and one used Carkhuff (1969) ratings. Six of the studies have been correlational and one phenomenological; in one the researcher tested hypotheses by means of a quasiexperimental design.

For studies in which researchers examined trainees at various levels of development, the methodology has been more varied. In 6 of 12 studies, researchers used multiple training sites, though in 11 of the 12 the researchers sampled university counseling centers. The national samples have ranged from 3 sites (M. L. Friedlander \& Snyder, 1983) to 35 sites (M. L. Friedlander \& Ward, 1984). Because of wide geographical range of samples, only one study involved measurement of actual behavior during supervision (Raphael, 1982). In most (7 of 12) the researchers used the Supervision Questionnaire, its revision (Worthington, 1984a), or items taken from it. Two researchers used modifications of the CRF. Wiley (1982) and Reising and Daniels (1983) created their own instruments. M. L. Friedlander and Ward (1984) created the Supervisory Styles Inventory and performed five independent studies of its reliability and validity, which constitutes the best psychometric data on an instrument designed specifically to measure supervision. In 8 of the 12 studies, hypotheses were tested in a quasiexperimental design.

\section{What Is Known}

1. There is some support for general developmental models as proposed by Hogan (1964) and others (e.g., Stoltenberg, 1981, and Loganbill et al., 1982). However, Holloway (1987) critically evaluated the extent to which the assumptions of a developmental model have been met by the theories and research purporting to take a developmental perspective, and she took issue with this conclusion.

2. In general, perceptions of supervisors and supervisees have been broadly consistent with developmental theories. Reising and Daniels (1983) tested some of Hogan's (1964) ideas and showed that from anxiety, need for techniques, and an unwillingness to be confronted to low need for work validation, counselors develop high independence but some ambivalence as to their role as a counselor. Reising and Daniels also found that counselors did not identify specific needs for supervision but rather described stereotypical ideas of a good supervisor. Despite their level of counselor development, their ideal supervisors were stereotyped, which suggests that counselors do not know how good supervision might differ for them as they gain counseling experience. An alternative interpretation of Reising and Daniels's findings is that it does not matter to counselors whether their supervisor supervises differently across levels of development; however, this interpretation is not supported by ratings of actual supervision, which show that actual supervision behavior differs with level of counselor development and that different supervisor behaviors are related to perceptions of supervisor effectiveness at different levels of counselor development.

Wiley (1982) tested aspects of Stoltenberg's (1981) theory. She operationalized Stoltenberg's four levels of counselor development by describing each level in terms of phrases that applied to a counselor at that level. She then described ideal environments for counselors at each level. Throughout the United States, 71 supervisors rated 107 of their supervisees on the list of descriptive phrases. The supervisors also described the environment that they believed they provided for each supervisee on a list of descriptive phrases. Wiley tested three main hypotheses. She found that the level of supervisor-rated development of their supervisees was related to the amount of supervised counseling experience of the counselor but not to the level of unsupervised counseling experience. She also found that the supervisors perceived themselves to be providing different levels of supervisory environment with supervisees of different levels of supervised counseling experience but not with supervisees of different levels of unsupervised counseling experience. Last, in a crucial test of Stoltenberg's theory, 
she found that congruence of supervisee's level of experience and supervision environment was unrelated to either supervisor's or supervisee's satisfaction with supervision. Generally, when supervisors did not match the supervision environment with the level of supervisee development, they differed by providing supervision at a level lower than the supervisee's level of development. There were few gross mismatches, which suggests that supervisors might intuitively match levels of counselor and supervision environment. Wiley's research is an excellent test of a theoretical position-a too-rare occurrence in the supervision literature-but it can be criticized because supervisors rated both the level of the supervisee and the level of environment that they tried to provide. There is no assurance that they actually provided the environment that they believed they provided. In fact, the structure of the task, in which supervisors were asked to make the ratings of supervisee and supervision environment at the same time, might have introduced demands for the supervisors to think more along developmental lines than they might usually do.

Miars et al. (1983) also investigated the counselor complexity model (Stoltenberg, 1981). Experienced supervisors described their supervision four times: for first-semester practicum, second-semester practicum, advanced practicum, and internship counselors (regardless of whether they had experience with supervisees at that level). They described themselves as conducting supervision differently depending on the level of the hypothetical student at that level. The supervisors reported the most variations across supervisee level in dimensions of structure, directiveness, instruction, and degree of collegiality. Supervisors' perceived supervisory environments paralleled Stoltenberg's expectations, though supervisors' expectations were less differentiated than Stoltenberg's (cf. Yogev \& Pion, 1984). Again, this study suffered from use of supervisors alone as participants. Worthington and Roehlke (1979) and Heppner and Roehlke (1984) found that supervisors perceived supervision differently than supervisees. Furthermore, all supervisors were drawn from a single university, in which there is generally a high consciousness of how counselors change as they gain experience.

Heppner and Roehlke (1984), using three studies, examined beginning practicum, ad- vanced practicum, and intern counselor trainees. The supervision dyads were composed of beginning practicum counselors with intern supervisors, advanced practicum counselors with mostly doctoral-level supervisors, and intern counselors with doctoral-level supervisors. In the first study, Heppner and Roehlke (1984) found that before the beginning of supervision, supervisees at different levels of experience had (a) essentially the same expectations about supervisor expertness, attractiveness, and trustworthiness and (b) the same locus of control scores. At the beginning of supervision, supervisees also did not differ in their perceptions of the expertness, attractiveness, and trustworthiness of their supervisors. Neither supervisee characteristics nor initial perceptions of supervisors were related to the actual impact of supervision or to each other. This was also found by M. L. Friedlander and Snyder (1983), who used similar methodology with 82 trainees at beginning practicum, advanced practicum, and internship levels in three states.

In their second study, Heppner and Roehlke (1984) used the SQ (Worthington \& Roehlke, 1979) and three additional items to compare the supervision behaviors perceived by supervisees of different levels of experience. They correlated each supervisor behavior with supervisees' ratings of satisfaction, supervisor competence, and perceived impact of supervision on counseling ability. Beginning practicum counselors were more satisfied with supervisors who fostered a positive relationship with the supervisee. Advanced practicum students were more satisfied with supervisors who facilitated development of additional counseling skills. Interns were more satisfied with supervisors who helped them to develop better counseling skills and allowed them to deal with personal issues or defensiveness that affect counseling. Results might be attributable to the nature of the sample: It was from one university counseling center. Worthington (1984a) surveyed 237 counselors from ten counseling centers nationwide. He too determined SQ behaviors that were related to perceptions of satisfaction with supervision, of competence of the supervisor, and of impact on counseling ability. Grouping items according to 12 factor-analytic clusters, he found that (a) his factors were similar to many of those found by Reising and Daniels (1983), (b) support and encouragement were useful at first practicum 
level and at the internship level, times when issues of identity were at the forefront, (c) skills of intervention and conceptualization were built throughout all five levels of counselor experience that were investigated, and (d) perceptions of satisfaction and supervisor competence were predicted by support and teaching (Heppner \& Roehlke, 1984; Worthington \& Roehlke, 1979), but perceptions of supervisor impact on the counselor's ability were also related to evaluation and teaching advanced skills (cf. Heppner \& Roehlke, who reported that essentially the same factors were predictive of all three measures of supervision effectiveness). Taken together, Heppner and Roehlke's and Worthington's studies provide limited but reasonably congruent support for developmental models of supervision. Worthington's findings also support Hess's (1986) notion of spirals, in which the same issues are addressed at progressively deeper levels throughout training (see also Loganbill et al., 1982).

In their third study, Heppner and Roehlke (1984) examined some of the critical incidents in supervision. They found that support was valued across the three levels of experience. Emotional awareness, confrontation, and competency issues constituted critical incidents for practicum students far more frequently than for interns. Interns reported critical incidents involving parallel process and discussion of transference and countertransference issues more frequently than did practicum students. These results too lent support for the general flavor of developmental theories.

One hole in the investigation of developmental theories is in understanding the master counselor stage. Zucker and Worthington (1986) examined differences between interns and postdoctoral applicants for licensure who were being supervised. They studied a national sample of 34 interns and 25 psychologists. Few differences were found between the two levels of experience. Psychologists received supervision that was generally less evaluative than interns' supervision. Advanced supervision of interns and postdoctoral psychologists consisted of support and rapport, feedback, confrontation and evaluation, and negative feedback. Zucker and Worthington concluded that investigation of supervision of master counselors required sampling counselors who had more experience than recent graduates so that the experienced professional counselor could be clearly differentiated from advanced trainees.

Virtually all of these studies of how supervision changes as counselors gain experience have supported the general tenets of developmental theories, though most of the details of the theories have not been investigated. Ideas about how counselors develop (see Hill et al., 1981) are more in line with developmental theory than are the mechanics of matching supervision to the different levels.

3. The behavior of supervisors changes as counselors gain experience. Raphael (1982) compared supervision with trainees in either their first or second practicum against those with four or more semesters of practicum. $\mathrm{He}$ developed a nine-category system for classifying verbal responses of supervisors. For example, supervisors could focus on the client, the therapy relationship with the client, the therapy relationship with the therapist, the therapy relationship with both, feelings and thoughts of the therapist about the therapy session, the therapist apart from the session, the supervisory relationship, the supervisor, or "other." Supervisors' statements were sampled from tapes of actual supervision. Supervisors did not differ in frequency of statements with counselors of different experience levels; however, the distribution differed across level of experience. Supervisors of advanced trainees made higher proportions of statements that focused on (a) the client, (b) the client in therapy, and (c) the supervisor. Supervisors of beginning trainees made higher proportion of statements that focused on (a) the counselor's behavior in therapy, (b) the counselor's feelings and thoughts about therapy, and (c) the supervisory relationship.

These findings are consistent with research on perceptions of supervisors and supervisees about supervisor behavior during supervision. For instance, in most studies of both supervisees' and supervisors' perceptions of their behavior, researchers have found that supervisors teach specific behaviors about therapy to beginning-level counselors (see studies reviewed in Point 2). Beginning counselors are also usually insecure and lack self-confidence (Heppner \& Roehlke, 1984; Reising \& Daniels, 1983; Worthington, 1984a), which suggests that supervision might focus on the counselor's thoughts and feelings about therapy. However, most supervisors and beginning supervisees 
perceive little focus on the supervisory relationship during supervision. Focus on the supervisory relationship usually is perceived to occur at internship-level supervision. Focus on the client and the therapist during therapy are often perceived to occur at the practicum level. However, focus explicitly on the supervisor is usually characteristic of supervision of more advanced counselors (intern and beyond) who share mutuality and collegiality.

In other studies researchers have examined supervisor behavior at only one level of counselor experience. Rickards (1984) examined 28 beginning counselors, excerpting 20-min segments from supervision sessions and scoring them with the Blumberg System for Analyzing Supervisor-Teacher Interactions (Blumberg, 1980). The Blumberg system comprises 15 categories: 10 supervisor and 5 supervisee behaviors. Rickards (1984) found that perceptions of supervisor expertness, attractiveness, and trustworthiness were moderately related to counselor supervision behavior. Criticisms and opinions given by supervisors were negatively related to counselor perceptions of positive supervisor qualities. Counselors who expressed negative social-emotional behavior and who failed to ask for information were also perceived negatively by their supervisors. Holloway and Wampold (1983) used the Blumberg system with supervision dyads involving beginning counselors and found the same results. Their outcome measures, though, were not ratings of supervisor expertness, attractiveness, and trustworthiness but were self-report measures of satisfaction with supervision by both supervisors and supervisees. Again, critical supervisor responses spoiled what were ordinarily high ratings of satisfactions with supervision by supervisees. Supervisors did not like periods of silence and did not like counselors to support them for giving opinions. When the supervisor followed the trainees' expression of ideas with requests for more ideas, satisfaction with supervision was high for both supervisors and supervisees. However, use of supportive communication produced mixed reactions from supervisors and supervisees. One might surmise that both parties liked to be shown that their ideas were appreciated but did not necessarily like the other party to verbalize that appreciation.

4. The supervision relationship changes as counselors gain experience. The relationship between supervisor and supervisee is influenced by the supervisee's perceptions of his or her supervisor. Heppner and Handley (1981) found that counselors' perceptions of their supervisors as expert, attractive, and trustworthy were consistently correlated with a positive supervisory relationship and with satisfaction with supervision. Dodenhoff (1981) also found that when counselors liked their supervisors, supervisors liked them and thought them to be more effective. Client ratings of the counselors' effectiveness did not substantiate the ratings of the supervisors.

In only one paper did the authors investigate the effect of experience level of counselors on the supervision relationship. Worthington and Stern (1985) studied supervision relationships of pre- and post-master's-level counselors with pre- and postdoctoral-level supervisors at one university. Supervisees perceived their relationships with their supervisors to change throughout the semester. Generally, supervisees rated their relationship with their supervisors lowest after 5 weeks of the semester and higher after 10 and 15 weeks into the semester. Supervisors did not perceive a difference in their relationships with their supervisees at the three times during the semester. Supervisee experience affected perceptions of the development of the relationships. Supervisors perceived that their relationships with master's students were more helpful at 15 weeks than at 5 weeks into the semester. Supervisors did not perceive their helpfulness to doctoral students to differ at any of the three measurement times. Counselors at the master's level perceived their relationships to be more positive with their supervisors than counselors at the doctoral level. In general, master's-level counselors rated their supervisory relationships as steadily improving. Worthington and Stern speculated that supervisors get to know formerly unknown master's students during supervision but have ongoing relationships with doctoral students. They also offered a second hypothesis that master's-level counselors might be more responsive to their supervisors' suggestions, thus causing their supervisors to like them more (see Dodenhoff, 1981). A final hypothesis was that doctoral counselors are more likely to be in the stage of orthodoxy (Hill et al., 1981) and thus are less likely to be open to suggestions from supervisors who differ in theoretical stance from them. 
Results from a variety of studies with a variety of methodologies are clear. Supervisees perceive that their supervisors give different types of supervision to them when they are at different levels of training. As counselors advance, they perceive supervisors to confront, deal with personal issues, tackle client resistance and transference/countertransference issues, give negative feedback, and treat them like peers more often. Furthermore, supervisors are perceived to give less instruction, provide less structure, monitor the behavior of the supervisee less, and be less directive.

\section{What Is Missing}

Although these findings are consistent with the various developmental models-which are remarkably consistent with each otherresearch has failed to answer a number of important questions.

1. Do changes in supervision as counselors gain experience promote growth and improvement of the supervisee, or do they merely satisfy the supervisee? Few studies of supervision have included measures of clients' improvement (cf. Dodenhoff, 1981; Lambert, 1974) or clients' perception of the counselor.

2. Within specific theoretical approaches to counseling, how do supervisor behaviors relate to counselor development over time?

3. Until now, researchers have been concerned with identifying good supervisor behaviors: those that contribute to supervisee satisfaction, those that show supervisor competence, and those that affect the supervisee's counseling. A good theory of lousy supervisor behaviors is missing. What can the supervisor do to prohibit movement from one stage of counseling to another? What can the supervisor do to contribute to dissatisfaction with supervision? How can poor counseling outcomes be engendered? Although this sounds somewhat facetious, the need is real. We need to spend more creative thought in identifying the things that we do to contaminate supervision (see Hutt, Scott, \& King, 1983; C. D. Miller \& Oetting, 1966; Rickards, 1984; Rose, 1965; Rosenblatt \& Mayer, 1975).

4. Most theories of development of the counselor focus on the stages through which the counselor passes. Little attention has been given to how the counselor makes the transition from one stage to the next and, specifically, to how the supervisor can accelerate (or retard, if that seems appropriate) the counselor's progress from each stage to the next.

5. What is the supervision relationship like? Most studies have focused on the supervision behaviors or styles but not on the characteristics of the relationship (cf. Hutt et al., 1983; Worthington \& Stern, 1985).

6. What kinds of influence strategies are used by supervisors, and how do they work on the supervisee who becomes increasingly psychologically sophisticated as experience is accrued? Studies on influence strategies to date have been concerned with applying Strong's (1968) interpersonal influence model, which specified source characteristics of the influencer, to supervision. The support for this model has been weak ( Heppner \& Handley, 1981, 1982; Heppner \& Roehlke, 1984; Rickards, 1984). More sophisticated influence strategies, developed in counseling (e.g., Kiesler, 1986; Strong, 1986), should be applied to supervision and investigated. Theories are needed to describe the influence strategies of supervision, comparing and contrasting them with psychotherapy.

7. Gender matching has been found to affect the supervision relationship; matching according to cognitive style has not influenced the relationship. Would matching on other variables affect the process and outcomes of supervision? One variable of potential importance is theoretical orientation. One would expect that during the early years of counselor training, matching supervisors and supervisees according to theory would be of little importance because of the theoretical flexibility of the neophyte counselor. By advanced practicum or internship, though, most trainees adhere to a counseling theory (Hill et al., 1981). Having a theoretical mismatch between counselor and supervisor might produce dissatisfaction with supervision, especially if the supervisor is also strongly committed to a theoretical stance. At the advanced or master counselor stages, matching according to theoretical persuasion might again have little impact on supervision.

8. Exactly what is it about supervised experience in counseling that helps a counselor to become more proficient? Wiley's (1982) finding that counselors get better with supervised counseling experience but not just counseling 


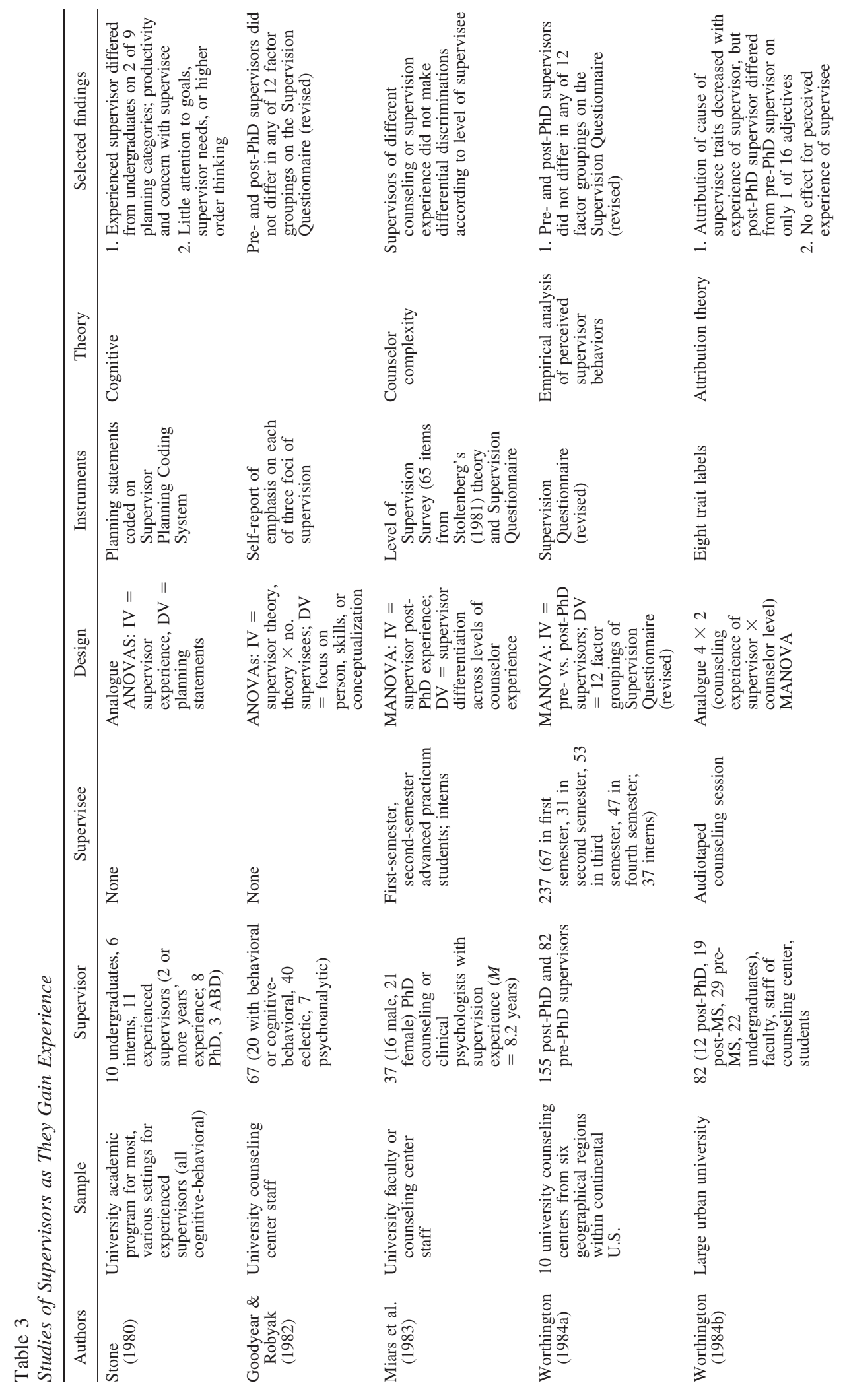




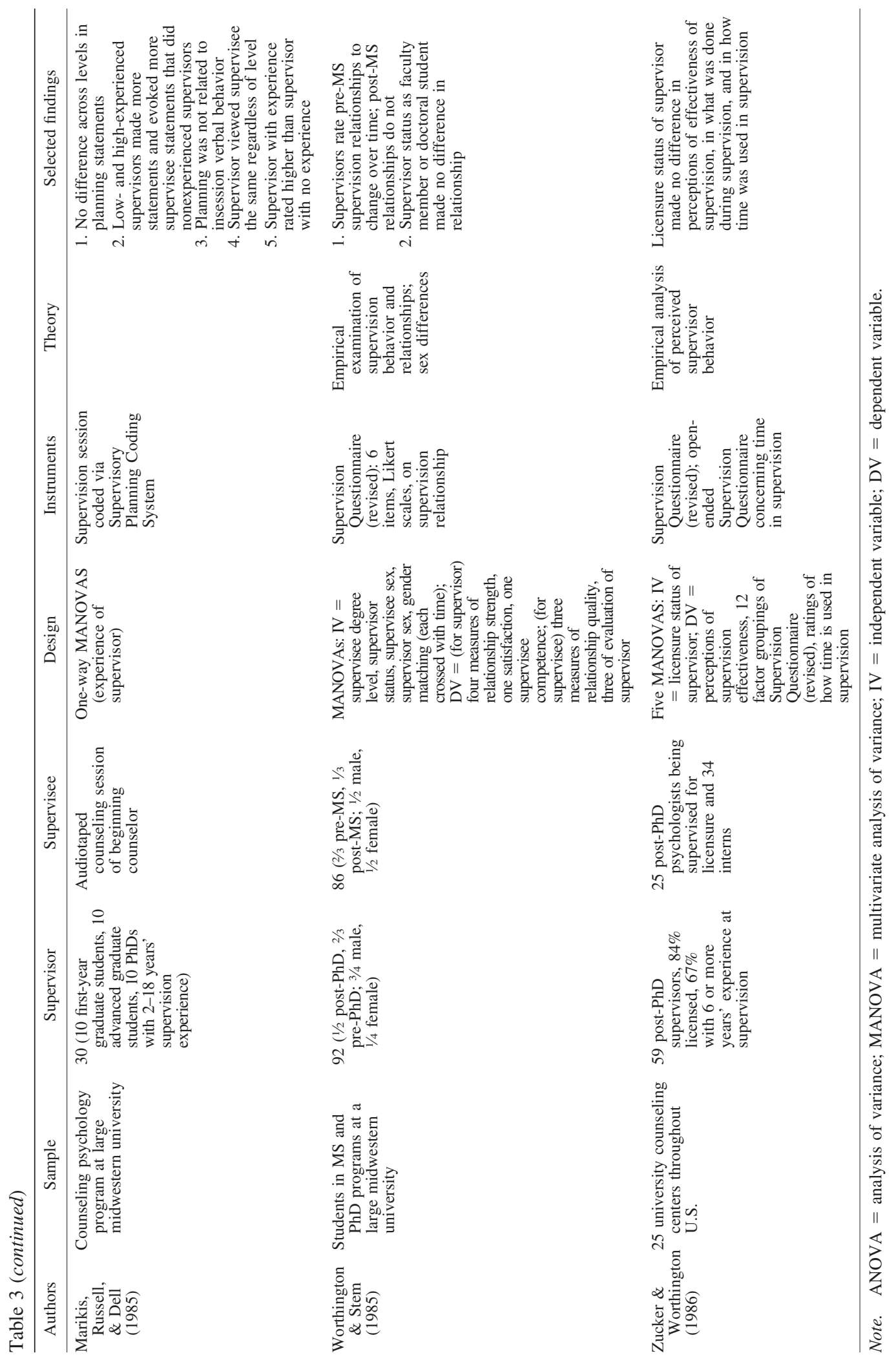


experience is provocative. It could suggest a parallel to Freud's notion that one cannot know one's own unconscious but needs an objective analyst to help. Perhaps counselors find it difficult to know their own counseling and improve it. Counselors create cognitive maps of their experience (theories and models) that guide their perceptions of their own behavior, goals, and understanding of how they counsel. Without supervision to challenge their cognitive maps, few counselors will systematically audiotape or videotape to inject an impartial view of their counseling. Few will allow their work to be viewed by others. Clients' comments about counseling style are often dismissed as being from a naive source. Counselors believe that they are actually counseling the way they say they are, but, as most supervisors know, the way in which a counselor talks about his or her counseling is not perfectly correlated with the way in which he or she counsels. It is the systematic analysis of a counselor's behavior from a different viewpoint than one's own that helps a counselor to change self-perception and behavior.

\section{The Developing Supervisor: Empirical Research}

\section{What Is Known}

1. There are differences in skillfulness in supervision across supervisors. In several investigations of the effectiveness of supervision, researchers have found a variety of levels of supervisor competence and impact (see Cross \& Brown, 1983; Heppner \& Handley, 1981; Worthington, 1984a; Worthington \& Roehlke, 1979; Worthington \& Stern, 1985; Zucker \& Worthington, 1986). Furthermore, Hester, Weitz, Anchor, and Roback (1976) found that perceived differences in supervisor skillfulness are related to attraction of supervisees to supervisors (see Table 3 ).

2. Supervisors do not become more competent as they gain experience. Once supervisors reach the advanced practicum level of experience, they can apparently supervise with effectiveness equal to that of post-PhD supervisors. Marikis, Russell, and Dell (1985) studied students in their first practicum, students in their advanced practica, and post-PhD counselors.
All acted as supervisors during a 30-min supervision interview with a counselor. Post-master's students were rated as effective as post-PhD supervisors, though both groups were rated as more effective supervisors than beginning practicum counselors. Marikis et al. (1985) found that the two groups of experienced supervisors addressed counseling skills of the counselor and talked about themselves as supervisors more than did beginning practicum students. Overall, the more experienced supervisors talked less than beginning counselors. In none of the three comparisons did post-master's counselors differ from post-PhD counselors. Worthington (1984a) surveyed 237 supervisees nationwide and also found that pre- and post$\mathrm{PhD}$ supervisors in actual supervision of counselors from first practicum to internship were not rated as differentially effective in terms of their competence, their impact on the supervisee, or satisfaction of the supervisee with supervision.

Zucker and Worthington (1986) wondered whether licensure status of the supervisors of interns and postdoctoral candidates for licensure affected the quality of supervision. They surveyed 59 psychologists and interns nationwide. The supervisors were generally very experienced. (Only one third had less than 6 years of experience.) When years of post-PhD experience was used as a covariate, licensure status of the supervisor did not affect supervisees' ratings of the effectiveness of supervision. Also, in no case was the covariate (years of experience) significant.

Worthington and Stern (1985) surveyed 92 supervisors and 86 supervisees at one university. They found that neither supervisors nor supervisees rated supervisors as more effective depending on their status as either faculty (or senior staff) or students (interns or advanced practicum students). There were also no perceived differences in the quality or strength of the supervision relationships that were attributable to faculty or student status of the supervisor.

In sum, whether supervision experience is conceptualized as degree level, licensure status, or student-faculty status, supervisors beyond the master's level do not appear to differ in effectiveness of supervision.

3. Supervisors change little in other ways as 
they gain experience. Miars et al. (1983) divided supervisors into those with low (1-5 years), medium (6-11 years), and high (12 years and beyond) levels both of post-PhD counseling experience and of supervision experience. They found that supervisors did not make differential discrimination of counselor needs as counselors gained experience.

Goodyear and Robyak (1982) divided supervisors into those with $0-8$ years of post-PhD experience versus those with 9 or more years of experience. They found no difference across levels of experience in focus of the supervisor on the person of the supervisee, in the skills of the counselor, or in the conceptualization of the client's problems. Goodyear and Robyak then divided supervisors into those who had supervised fewer than 25 supervisees and those with 25 or more. Again, no main effects were found for supervision experience. One interaction was found between supervisor theory and supervisor experience. Behavioral counselors with fewer supervisees focused more on counseling skills than either behavioral counselors with more supervisees or eclectic supervisors with fewer supervisees.

Worthington (1984b) had "supervisors" at the undergraduate, pre-master's, post-master's, and post-PhD levels rate a counselor on the basis of hearing $10 \mathrm{~min}$ of excerpts from an audiotaped counseling session. There were clear differences across all levels of supervisor experience in the attributions made to the counselor; however, most of the differences occurred between the undergraduates and the other three levels of experience. Only one of eight comparisons showed differences between post-PhD and post-master's supervisors.

Stone (1980) and Marikis et al. (1985) investigated whether supervisors at different levels of experience made different planning statements before supervision. Stone (1980) found that undergraduate students differed from post- $\mathrm{PhD}$ supervisors in only two of nine categories of planning statements: focus on the supervisee and number of statements. Marikis et al. (1985) found that pre- and post-PhD supervisors did not differ on any category of planning statements, but beginning practicum students did differ from the more experienced supervisors on three of nine categories.

\section{What Is Missing}

1. Although evidence to date shows little indication that supervisors improve with experience, this does not mean that they do not change with experience. The inexperienced supervisor might contribute different benefits to the supervisee. For example, the new supervisor might promote identification with himself or herself because he or she is or has recently been a student. The new supervisor might be aware of the issues that the trainee is dealing with to a greater extent than the seasoned veteran supervisor is. The new supervisor might be enthusiastic, energetic, and willing to devote extra session time to the supervisee more readily than the experienced supervisor is. On the other hand, the experienced supervisor might have more technical expertise than the fledgling, being more facile with client assessment, counseling interventions, or technical skills. Although each supervisor is perceived to be effective and competent by the supervisee, each might clearly offer different resources to the supervisee and contribute to the counseling effectiveness of the supervisee in different ways.

Unwilling as we might be to accept it, most supervisors simply might not improve with experience. One reason for this might be that supervisors have little training in how to supervise effectively and thus may perpetuate the mistakes of their own supervisors. Wiley (1982) showed that with counselors, mere counseling experience was insufficient to produce change in counseling ability. The same might be true with mere supervision experience or mere longevity as a post-PhD professional. Mere experience might be insufficient to enable one to view one's work objectively or to take different perspectives on one's work. Perhaps a supervisor of one's supervision would promote improvement. There are few mechanisms for providing this supervision beyond the internship level, when supervised practice of supervision is even part of the internship. Hess and Hess (1983) found that in only about $40 \%$ of the internship training sites is there any ongoing training of supervisors. In only one third of the places in which interns were allowed to supervise, one-to-one supervision of supervision was given. McColley and Baker (1982) found that 
only about $50 \%$ of new supervisors had had any training in supervision. Only $20 \%$ had had a course or seminar in supervision.

2. The empirical investigation of how supervisors change with experience is at a rudimentary level. Few researchers have taken that question as a primary focus of research. This is probably because there have been few theoretical works about supervisors' development until recently.

3. Theories are still imprecise and general. The important variables affecting improvement in or even change in supervision must still be identified. For example, no one has yet investigated the amount of supervised experience in supervision, the amount of involvement in thinking about supervision (through writing papers, giving workshops, conducting classes, and so on), attendance at supervision-related continuing education functions, or involvement in peer consultation about one's supervision as they relate to changes in supervision practices or outcomes.

4. There is little specification of what makes a supervisor effective and thus of how one builds the skills necessary to become effective.

5. There is little understanding about how a supervisor might change in conceptual ability or in cognitive style as the supervisor gains experience.

\section{Conclusion}

In reference to the opening metaphor, if gaining experience at counseling and supervision is like the aging of wines, then this review uncovered two types of wines: counselors and supervisors. One type of wine, the counselor, changes and improves with age. Counselor trainers and supervisors pay attention to the counselor's aging and aid his or her development. The other type of wine, the supervisor, does not clearly improve with age. Supervisors appear to be neglected or given minimal attention by most professional environments, yet are expected to change with age and to age with quality. They are like a fine wine, bottled wholly in sterile glass without a cork that allows the wine to develop robustness. More attention is needed within the profession to the maturing of this wine into fullness.

\section{References}

Alonso, A. (1983). A developmental theory of psychodynamic supervision. The Clinical Supervisor, 1(3), 23-36.

Ard, B. N. (1973). Providing clinical supervision for marriage counselors: A model for supervisor and supervisee. The Family Coordinator, 22, 91-97.

Barak, A., \& LaCrosse, M. B. (1975). Multidimensional perception of counselor behavior. Journal of Counseling Psychology, 22, 471-476.

Barrett-Lennard, G. T. (1962). Dimensions of therapist responses as a causal factor in therapeutic changes. Psychological Monographs, 76 (43, Whole No. 562).

Bartlett, W. E., Goodyear, R. K., \& Bradley, F. O. (Eds.) (1983). Special issue: Supervision in counseling II. The Counseling Psychologist, 11(1), 7-79.

Bernard, J. M. (1979). Supervisor training: A discrimination model. Counselor Education and Supervision, 19, 60-68.

Bernard, J. M. (1981). Inservice training for clinical supervisors. Professional Psychology, 12, 740748 .

Bernard, J. M. (1982). Laboratory training for clinical supervisors: An update. Paper presented at the annual meeting of the American Psychological Association, Washington, DC.

Blount, C. M. (1982). A developmental model of supervision: Implications for practice and research. Paper presented at the annual meeting of the American Psychological Association, Washington, DC.

Blumberg, A. (1980). Supervision of teachers (2nd ed.) Berkeley, CA: McCutchan.

Carkhuff, R. R. (1969). Helping and human relations. New York: Holt, Rinehart \& Winston.

Cross, D. G., \& Brown, D. (1983). Counselor supervision as a function of trainee experience: Analysis of specific behaviors. Counselor Education and Supervision, 22, 333-341.

Crowne, D., \& Marlowe, D. (1964). The approval motive. New York: Wiley.

Dodenhoff, J. T. (1981). Interpersonal attraction and direct-indirect supervisor influence as predictors of counselor trainee effectiveness. Journal of Counseling Psychology, 28, 47-52.

Fleming, J. (1953). The role of supervision in psychiatric training. Bulletin of the Menninger Clinic, 17, 157-159.

Forsyth, D. R., \& Ivey, A. E. (1980). Microtraining: An approach to differential supervision. In A. K. Hess (Ed.), Psychotherapy supervision: Theory, research, and practice (pp. 242-261). New York: Wiley.

Friedlander, M. L., \& Snyder, J. (1983). Trainees' expectations for the supervisory process: Testing a 
developmental model. Counselor Education and Supervision, 22, 342-348.

Friedlander, M. L., \& Ward, L. G. (1984). Development and validation of the Supervisory Styles Inventory. Journal of Counseling Psychology, 31, 541-557.

Friedlander, S. R., Dye, N. W., Costello, R. M., \& Kobos, J. C. (1984). A developmental model for teaching and learning in psychotherapy supervision. Psychotherapy, 21, 189-196.

Gaoni, B., \& Neumann, M. (1974). Supervision from the point of view of the supervisee. American Journal of Psychotherapy, 24, 108-114.

Goodyear, R. K., \& Robyak, J. E. (1982). Supervisors' theory and experience in supervisory focus. Psychological Reports, 51, 978.

Grotjahn, M. (1955). Problems and techniques of supervision. Psychiatry, 18, 9-15.

Handley, P. (1982). Relationship between supervisors' and trainees' cognitive styles and the supervision process. Journal of Counseling Psychology, 29, 508-515.

Hart, G. M. (1982). The process of clinical supervision. Baltimore: University Park Press.

Heppner, P. P., \& Handley, P. G. (1981). A study of the interpersonal influence process in supervision. Journal of Counseling Psychology, 28, 437-444.

Heppner, P. P., \& Handley, P. (1982). The relationship between supervisory behaviors and perceived supervisor expertness, attractiveness, or trustworthiness. Counselor Education and Supervision, 22, 37-46.

Heppner, P. P., \& Roehlke, H. J. (1984). Differences among supervisees at different levels of training: Implications for a developmental model of supervision. Journal of Counseling Psychology, 31, 7690.

Hess, A. K. (Ed.) (1980). Psychotherapy supervision: Theory, research, and practice. New York: Wiley.

Hess, A. K. (1986). Growth in supervision: Stages of supervisee and supervisor development. The Clinical Supervisor, 4, 51-67.

Hess, A. K., \& Hess, K. A. (1983). Psychotherapy supervision: A survey of internship training practices. Professional Psychology: Research and Practice, 14, 504-513.

Hester, L. R., Weitz, L. J., Anchor, K. N., \& Roback, H. B. (1976). Supervisor attraction as a function of level of supervisor skillfulness and supervisees' perceived similarity. Journal of Counseling Psychology, 23, 254-258.

Hill, C. E., Charles, D., \& Reed, K. G. (1981). A longitudinal analysis of changes in counseling skills during doctoral training in counseling psychology. Journal of Counseling Psychology, 28, 428-436.
Hogan, R. A. (1964). Issues and approaches in supervision. Psychotherapy: Theory Research and Practice, 1, 139-141.

Holloway, E. L. (1987). Developmental models of supervision: Is it development? Professional Psychology: Research and Practice, 18, 209-216.

Holloway, E. L., \& Wampold, B. E. (1983). Patterns of verbal behavior and judgments of satisfaction in the supervision interview. Journal of Counseling Psychology, 30, 227-234.

Hutt, C. H., Scott, J., \& King, M. (1983). A phenomenological study of supervisees' positive and negative experiences in supervision. Psychotherapy: Theory, Research and Practice, 20, 118-123.

Kagan, N. (1980). Influencing human interactionEighteen years with IPR. In A. K. Hess (Ed.), Psychotherapy supervision: Theory, research, and practice (pp. 262-283). New York: Wiley.

Kiesler, D. J. (1986). Interpersonal methods of diagnosis and treatment. In J. O. Cavenar (Ed.), Psychiatry (Vol. 1, pp. 1-23). Philadelphia: Lippincott.

Kirchner, K. R. (1975). Expectations about individual counseling supervision. Dissertation Abstracts International, 36, 445B. (University Microfilms No. 75-16, 012)

Kurtz, P. D., Marshall, E. K., \& Banspach, S. W. (1985). Interpersonal skill-training research: A 12year review and analysis. Counselor Education and Supervision, 24, 249-263.

Lambert, M. J. (1974). Supervisory and counseling process: A comparative study. Counselor Education and Supervision, 14, 54-60.

Leddick, G. R., \& Bernard, J. M. (1980). The history of supervision: A critical review. Counselor Education and Supervision, 19, 186-196.

Littrell, J. M., Lee-Borden, N., \& Lorenz, J. A. (1979). A developmental framework for counseling supervision. Counselor Education and Supervision, 19, 129-136.

Loganbill, C., Hardy, E., \& Delworth, U. (1982). Supervision: A conceptual model. The Counseling Psychologist, 10(1), 3-42.

Marikis, D. A., Russell, R. K., \& Dell, D. M. (1985). Effects of supervisor experience level on planning and in-session supervisor verbal behavior. Journal of Counseling Psychology, 32, 410-416.

McColley, S. H., \& Baker, E. L. (1982). Training activities and styles of beginning supervisors: A survey. Professional Psychology, 13, 283-292.

Miars, R. D., Tracey, T. J., Ray, P. B., Cornfeld, J. L., O'Farrell, M., \& Gelso, C. J. (1983). Variation in supervision process across trainee experience levels. Journal of Counseling Psychology, 30, 403 412.

Miller, C. D., \& Oetting, E. R. (1966). Students react to supervision. Counselor Education and Supervision, 6, 73-74. 
Miller, R. (1982). Supervision: A conceptual model. The Counseling Psychologist, 10(1), 47-48.

Phillips, S. D. (Ed.) (1984). Special issue: Computers in counselor training. Counselor Education and Supervision, 24, 130-221.

Raphael, R. D. (1982). Supervisee experience: The effect on supervisor verbal responses. Paper presented at the annual meeting of the American Psychological Association, Washington, DC.

Reising, G. N., \& Daniels, M. H. (1983). A study of Hogan's model of counselor development and supervision. Journal of Counseling Psychology, 30, 235-244.

Rickards, L. D. (1984). Verbal interaction and supervisor perception in counselor supervision. Journal of Counseling Psychology, 31, 262-265.

Rose, S. D. (1965). Students view their supervision: A scale analysis. Social Work, 10, 90-96.

Rosenblatt, A., \& Mayer, J. E. (1975). Objectionable supervisor styles: Students' views. Social Work, 20, 184-188.

Sansbury, D. L. (1982). Developmental supervision from a skills perspective. The Counseling Psychologist, 10(1), 53-57.

Stoltenberg, C. (1981). Approaching supervision from a developmental perspective: The counselor complexity model. Journal of Counseling Psychology, 28, 59-65.

Stone, G. L. (1980). Effects of experience on supervisor planning. Journal of Counseling Psychology, 27, 84-88.

Strong, S. R. (1968). Counseling: An interpersonal influence process. Journal of Counseling Psychology, 15, 215-224.

Strong, S. R. (1986). Interpersonal influence theory and therapeutic interactions. In F. J. Dorn (Ed.), Social influence processes in counseling and psychotherapy, (pp. 17-30). Springfield, IL: Charles $\mathrm{C}$ Thomas.

Tyler, J. D., \& Weaver, S. H. (1981). Evaluating the clinical supervisee: A survey of practices in grad- uate training programs. Professional Psychology, 12, 424-437.

Wiley, M. O'L. (1982). Developmental counseling supervision: Person-environment congruency, satisfaction, and learning. Paper presented at the annual meeting of the American Psychological Association, Washington, DC.

Worthington, E. L. Jr. (1984a). An empirical investigation of supervision of counselors as they gain experience. Journal of Counseling Psychology, 31, 63-75.

Worthington, E. L. Jr. (1984b). Supervisors as empathic observers of counselor behavior. Professional Psychology: Research and Practice, 15, 457-461.

Worthington, E. L. Jr., \& Roehlke, H. J. (1979). Effective supervision as perceived by beginning counselors-in-training. Journal of Counseling Psychology, 26, 64-73.

Worthington, E. L. Jr., \& Stern, A. (1985). The effects of supervisor and supervisee degree level and gender on the supervisory relationship. Journal of Counseling Psychology, 32, 252-262.

Yogev, S. (1982). An eclectic model of supervision: A developmental sequence for beginning psychotherapy students. Professional Psychology, 13, 236-243.

Yogev, S., \& Pion, G. M. (1984). Do supervisors modify psychotherapy supervision according to supervisees' levels of experience? Psychotherapy, 21, 206-208.

Zucker, P. J., \& Worthington, E. L. Jr. (1986). Supervision of interns and postdoctoral applicants for licensure in university counseling centers. Journal of Counseling Psychology, 33, 87-89.

Originally published in Professional Psychology: Research and Practice, 1987, 18, 189-208. 